\title{
Polyvinylpyrrolidone-resorcinol-formaldehyde hydrogel system reinforced with bio-synthesized zinc-oxide for water shut-off in heterogeneous reservoir: An experimental investigation
}

\author{
Reena $^{1}$, Abhinav Kumar ${ }^{2}$ (D), Vartika Srivastava ${ }^{1}$, Vikas Mahto ${ }^{2,}$, and Abhay Kumar Choubey ${ }^{1}$ \\ ${ }^{1}$ Division of Sciences \& Humanities, Rajiv Gandhi Institute of Petroleum Technology, 229304 Jais, India \\ ${ }^{2}$ Department of Petroleum Engineering, Indian Institute of Technology (Indian School of Mines) Dhanbad, \\ 826004 Jharkhand, India
}

Received: 2 February 2021 / Accepted: 22 July 2021

\begin{abstract}
This work aims at evaluating advancement in water shut-off performance using nanocomposite hydrogel (PVP-ZnO:RF) prepared from PolyVinylPyrrolidone (PVP); used as polymer, Resorcinol-Formaldehyde $(\mathrm{RF})$; used as a crosslinker and nano Zinc Oxide $(\mathrm{ZnO})$; used as strength modifier and it was compared with conventional hydrogel (PVP:RF) i.e., hydrogel without $\mathrm{ZnO}$ nanofiller. The $\mathrm{ZnO}$, used as a nanofiller in this work, was successfully bio-synthesized (i.e., green route synthesized) from plant extract (Moringa oleifera leaves) and the average size was found to be $10 \mathrm{~nm}$. In this research work, the effect of $\mathrm{ZnO}$ nanofiller on gelation time, gel strength, thermal stability, rheological properties and water shut-off performance was systematically evaluated. On the incorporation of $\mathrm{ZnO}$ nanofiller, gelation time decreases but gel strength increases. The thermal stability of hydrogel was studied using a Differential Scanning Calorimeter (DSC) that depicts maximum tolerable temperature increases from $86{ }^{\circ} \mathrm{C}$ to $92{ }^{\circ} \mathrm{C}$ at 0.5 wt.\% of $\mathrm{ZnO}$ concentration in nanocomposite hydrogel (PVP). The mechanical stability of the nanocomposite hydrogel (PVP-ZnO:RF) demonstrates that infusion of $\mathrm{ZnO}$ nanofiller has significantly enhanced the dynamic moduli (i.e., storage modulus $\left(G^{\prime}\right)$ and loss modulus $\left.\left(G^{\prime \prime}\right)\right)$. Moreover, the optimum results of storage modulus $\left(G^{\prime}\right)$ and loss modulus $\left(G^{\prime \prime}\right)$ are found at 0.5 wt.\% of $\mathrm{ZnO}$ nanofiller. The water shut-off performance in the high permeable streak, in terms of percentage reduction in permeability, was $97 \%$ and $92 \%$ for nanocomposite hydrogel (PVP-ZnO:RF) and conventional hydrogel (PVP:RF), respectively. Also, the residual resistance factor is found to be 31.31 and 12.71 for PVP-ZnO:RF and PVP:RF hydrogels. Thus, the developed nanocomposite hydrogel (PVP-ZnO:RF) may be a promising solution to excessive water production in mature oil fields.
\end{abstract}

\section{Introduction}

Continuous increase in demand for energy and drastic decrease in the number of discoveries of new oil and gas fields across the globe have compelled the petroleum industries to increase the life of existing well in mature oil fields (Liu et al., 2010; Ma et al., 2019; Saikia and Sultan, 2020). In addition to this, an average oil recovery factor is as low as $30 \%$, i.e., around $70 \%$ of oil remains in the unswept hydrocarbon zones of reservoirs with severe heterogeneity (Kumar et al., 2020; Liu et al., 2017). Therefore, it has become necessary to prolong the life of mature hydrocarbon fields by using several techniques viz. advanced reservoir characterization, artificial-lift optimization, water shut-off, and different enhanced oil recovery methods (Abdulbaki et al., 2014; Kumar et al., 2020). Excess water production

\footnotetext{
* Corresponding author: vikas.ismpe@hotmail.com
}

is one of the significant problems over time while producing petroleum reserves which has a severe impact on the technical, environmental, and economic life of production well (Kalgaonkar et al., 2017; Tongwa and Baojun, 2015). Moreover, it has been estimated that an average cost of more than 40 billion US dollars is spent annually across the world to attenuate undesirable water from oil (Bailey et al., 2000). Recently, in mature oil fields, excess water production problems have drawn considerable attention as water production usually exceeds the economic limit, thus, compelling the petroleum industries to apply water shut-off techniques (Dang Cuong et al., 2011; Xindi and Baojun, 2017).

Reservoir heterogeneity due to induced fractures or high permeable streak is one of the pivotal factors of surplus water production which eventually leads to low sweep efficiency and reduction in petroleum recovery (Elsharafi and Bai, 2012; Kumar et al., 2019). Heterogeneity within the 
formation prevents the injected fluid from sweeping the unproduced oil from the mature oil fields, thus, causes higher Water to Oil Ratio (WOR) in the production well (Farasat et al., 2017; Liu et al., 2016). In addition to this, due to prolong water flooding in the reservoir for pressure maintenance in the reservoir results in a high water cut. The breakthrough within the producing well is a repercussion of heterogeneity along the high permeable zones which ultimately responsible for the abandonment of the production well (Sang et al., 2014; Sharifpour et al., 2015). In recent decades, various kinds of water shut-off techniques are purposed to improve the efficiency of unswept zones which directly impacts the incremental oil recovery (Elewaut et al., 2005). To overcome the issue of excessive water production due to the presence of reservoir heterogeneity, various chemical methods e.g., polymer, in-situ gel systems, particle gel systems, foams, etc. have been widely used in the oilfield globally (Al-Anazi and Sharma, 2002; Al-Muntasheri et al., 2007; Fuseni et al., 2018; Goudarzi et al., 2014; Wassmuth et al., 2004; Zhao et al., 2014). Among them, crosslinked in-situ polymer gel systems have been a cost-effective method and are usually applied for enhancing oil recovery by controlling excessive water production in mature oil fields (Moradi-Araghi, 2000; Zhu et al., 2017). In this technique, a polymer and crosslinker solution called gelant is injected into the formation to form a 3D gel network structure under reservoir conditions ( $\mathrm{pH}$, salinity, and temperature) to reduce the permeability of high permeable streak (Seright, 1991; Sydansk and Moore, 1992).

The major challenges associated with techniques are lack of control on gelation time, dilution of the gelant solution, loss of constituents because of adsorption on the rock surface and most of the time destabilization due to severe conditions (Goudarzi et al., 2015; Tongwa and Baojun, 2015). These challenges are encountered by the development of the nanocomposite hydrogel as it has better properties (i.e., thermal and mechanical stabilities) as compared to that of conventional hydrogels (Adewunmi et al., 2018; Lashari et al., 2018). Most of the researchers developed and widely studied nanocomposite hydrogels by reinforcing fillers in the hydrogel matrix. Among the most commonly used reinforced materials are nano-silica (Chen et al., 2018; Lashari et al., 2018), fly ash (Jiang and Liu, 2014; Singh et al., 2018), clays (Aalaie et al., 2008; Helvacioğlu et al., 2011; Okay and Oppermann, 2007; Tongwa et al., 2013), and carbon nanotubes (Evingür and Pekcan, 2014; Li et al., 2016; Sudha et al., 2014). However, organically modified fillers were also used to enhance the properties of hydrogel (Helvacıŏlu et al., 2011; Rezaei et al., 2016).

The present research work introduces zinc oxide as nanofiller material in nanocomposite hydrogel. The development of this research work is as follows: (1) the nanofiller material Zinc Oxide $(\mathrm{ZnO})$ was obtained by biosynthesis of plant extract from Moringa oleifera leaves; (2) a Zinc Oxide $(\mathrm{ZnO})$ reinforced nanocomposite hydrogel was synthesized from PolyVinyl Pyrrolidone (PVP); as polymer, Resorcinol and Formaldehyde (RF); as crosslinker and $\mathrm{ZnO}$; strength modifier; (3) the effect of nano zinc oxide on gelation time and gel strength was investigated at reservoir temperatures (4) thermal and rheological properties were studied; and (5) effectiveness of the nanocomposite hydrogel for water shutoff was examined using sandpack flooding experiments.

\section{Material and experimental methods}

\subsection{Materials}

PolyVinyl Pyrrolidone (PVP) (K-30, 98.0\%, M.W.: 40 000) was procured from Central Drug House Pvt. Ltd., India. Resorcinol and Formaldehyde (RF) were procured from Fisher Scientific with a purity of $99.0 \%$ to prepare crosslinker. Calcium chloride $\left(\mathrm{CaCl}_{2}\right)$, sodium hydroxide $(\mathrm{NaOH})$ and sodium chloride $(\mathrm{NaCl})$ were bought from Molychem, India. Sodium hydroxide is used to maintain the $\mathrm{pH}$ of the gelant solution between 8 and 9 .

\subsection{Biosynthesis of $\mathrm{ZnO}$ nanoparticles from plant extract (Moringa oleifera leaves)}

Moringa oleifera leaves were used to make the plant extract. Leaves were washed properly using distilled water. After that, leaves were dried in sunlight for 2-3 days. They were crushed into powdered form and heated with water for $2 \mathrm{~h}$. Further, Zinc acetate was added to the leaf extract and this extract was stirred for $6 \mathrm{~h}$ at $90^{\circ} \mathrm{C}$. The basic $\mathrm{pH}$ was maintained in the solution. Finally, the solution was filtered and washed with water and ethanol. The overall procedure was followed as per the research article of Srivastava and Choubey (2020).

\subsection{Reinforced nanocomposite hydrogel preparation}

PolyVinyl Pyrrolidone (PVP) solution (1.0 wt.\%) was prepared using $1.0 \mathrm{wt} . \% \mathrm{NaCl}$. The polymer solution was aged for $24 \mathrm{~h}$ at room temperature $(298 \mathrm{~K})$. $\mathrm{ZnO}(0.2 \mathrm{wt} . \%$, $0.5 \mathrm{wt} . \%, 0.8 \mathrm{wt} . \%$ and $1 \mathrm{wt} . \%$ ) was added to $5 \mathrm{~mL}$ distilled water and these samples were sonicated for $30 \mathrm{~min}$ for complete homogenization. Resorcinol (2.0 wt.\%) Formaldehyde (RF) was used as a crosslinker (R:F/1:0.1). After that, $\mathrm{ZnO}$ was mixed in the polymer solution. Digital ultrasonic cleaning was immediately performed in the solution of PVP-ZnO and homogenized for one hour. After complete homogenization, freshly prepared crosslinker solution (at room temperature) was added to the solution and stirred for $30 \mathrm{~min}$. The pH of PVP:RF (PolyVinyl Pyrrolidone - ResorcinolFormaldehyde) and PVP-ZnO:RF (Polyvinyl Pyrrolidone - Zinc Oxide - Resorcinol-Formaldehyde) hydrogels were adjusted approximately 9 . Eutech digital $\mathrm{pH}$ meter was used to maintain the $\mathrm{pH}$ of gel samples. The electrode of the $\mathrm{pH}$ meter was stored in $4 \mathrm{M} \mathrm{KCl}$ solution at room temperature. Initially, the prepared gelant solutions (PVP:RF \& PVP$\mathrm{ZnO}: \mathrm{RF}$ ) have a $\mathrm{pH}$ value between 4 and 5 (low $\mathrm{pH}$ ). In gel samples, higher $\mathrm{pH}$ was maintained (approximately 9) by adding few drops of $1 \mathrm{M} \mathrm{NaOH}$ solution and continuously checking the $\mathrm{pH}$ value until it reaches around 9 .

The ratio of polymer and crosslinker solution was 1:0.25. Lastly, the gelling solutions were poured into the ampoules 
Table 1. Gel strength codes of Bottle testing method are listed below.

\begin{tabular}{lll}
\hline Code & \multicolumn{1}{c}{ Gel type } & \multicolumn{1}{c}{ Gel behavior in bottle } \\
\hline A & No detectable gel & The gel solution appears to have almost the same fluidity as an initial solution \\
B & Highly flowing gel & The gel is comparatively slightly more viscous \\
C & Flowing gel & The gel flows up to the cap upon inversion \\
D & Moderately flowing gel & A small portion of gel does not flow to the cap upon inversion \\
E & Barely flowing gel & A small portion of gel slowly flows to the cap upon inversion \\
F & Highly deformable & No gel flow upon inversion (gel flows to just short of reaching the \\
non-flowing gel & bottle cap)
\end{tabular}

$(30 \mathrm{~mL})$ and ampoules were sealed at the neck using Teflon tape. Sealed ampoules were finally kept in an oven at $90{ }^{\circ} \mathrm{C}$.

Furthermore, the effect of salinity and temperature was also examined in conventional (PVP:RF) and reinforced nanocomposite (PVP-ZnO:RF; 0.5 wt.\% $\mathrm{ZnO}$ ) hydrogels. The $\mathrm{pH}$ of the gelling solution was raised from approx. 5 to approx. 9 by adding few drops of $1 \mathrm{M} \mathrm{NaOH}$ solution. The salinity effect was probed by using $\mathrm{NaCl}$ and $\mathrm{CaCl}_{2}$ salts. In the gelation study nanocomposite hydrogel (PVP-ZnO:RF; $0.5 \mathrm{wt} . \% \mathrm{ZnO}$ ) sample was compared with conventional hydrogel (PVP:RF).

\subsection{Characterization of $\mathrm{ZnO}$ filler}

The UV-vis spectrum measurements were performed using Lab India UV-Vis 3200 spectrophotometer over the region $300-800 \mathrm{~nm}$ by a $10 \mathrm{~mm}$ path length quartz cuvette. Powder X-Ray Diffraction (PXRD) data were evaluated by using a PANalytical X'pert Pro MPD diffractometer. The crystallinity of the samples was checked in the range of $20-80^{\circ}(2 \theta)$ with monochromatic radiation $\mathrm{Cu} \mathrm{K \alpha}$.

\subsection{Characterization of hydrogels}

Field Emission Scanning Electron Microscope (FESEM) images of gel samples were recorded to elucidate the morphological structure of gels. Before placing gel samples in a high vacuum environment, these samples were completely dried in an oven at $60{ }^{\circ} \mathrm{C}$. Proper drying of samples is an important parameter in FESEM analysis, otherwise, water evaporation will interfere and reduced image clarity of the sample surface. Images of samples are generated by operating FESEM in reflection mode. The conductive surface of the sample is required during this analysis. For this purpose, a thin layer of conductive surface is coated on the insulated sample surface. The gold coating was used for these gel samples for $105 \mathrm{~s}$. The microstructure of gel systems was examined using a Field Emission Scanning Electron Microscope (FESEM) on FESEM Zeiss Supra 40 (accelerating voltage ranged $15 \mathrm{kV}$ ).
Energy Dispersive X-Ray (EDX) analysis was also conducted on FESEM Zeiss Supra 40 (accelerating voltage ranged $15 \mathrm{kV}$ ) to identify the elemental composition of materials. The FTIR analysis of the samples was conducted for the functional group of the synthesized hydrogels using the Perkin Elmer Spectrum PIKE MIRacle spectrometer. The thermal stability of hydrogel systems was depicted from the Differential Scanning Calorimetry (DSC) profiles which were recorded on a Perkin Elmer DSC 4000 under an $\mathrm{N}_{2}$ atmosphere $(20 \mathrm{~mL} / \mathrm{min})$. The hydrogel samples (15-20 mg) were kept in an aluminum pan for thermal analysis in the temperature range of -20 to $200{ }^{\circ} \mathrm{C}$ with a continuous heating rate of $3^{\circ} \mathrm{C} \mathrm{min}^{-1}$.

\subsection{Determination of gelation time and gel strength}

The bottle testing method was adopted (Tab. 1) to investigate the gelation time of nanocomposite (PVP-ZnO:RF) and conventional (PVP:RF) hydrogels as this is an inexpensive method (Reena et al., 2020; Sydansk, 1990). The gelant solutions were visually checked after a specific time interval (at $50-90{ }^{\circ} \mathrm{C}$ ) to find out the gelation time.

The strength of gel samples can easily be influenced by several factors, viz. salinity, temperature, polymercrosslinker-nanoparticles concentration. Generally, the breakthrough vacuum method is used to determine the gel strength of gel samples because it is a cost-effective method. The experimental set-up for this method is shown in Figure 1. In this set-up, two suction flasks were used in series in this method. A glass tube was connected to one suction flask which was dipped in the ampoule containing gel sample. Another suction flask was connected to a vacuum pump. During the experiment, a sample tube containing $25 \mathrm{~mL}$ gel was taken. After that, a glass tube was placed into the sample tube and the vacuum pump was started. The suction pressure starts increasing and after a specific pressure, it falls rapidly. The maximum pressure attained was noted as gel strength because at this pressure gels rupture. All the experiments were repeated thrice to reduce the errors during experimentation and the reported final 


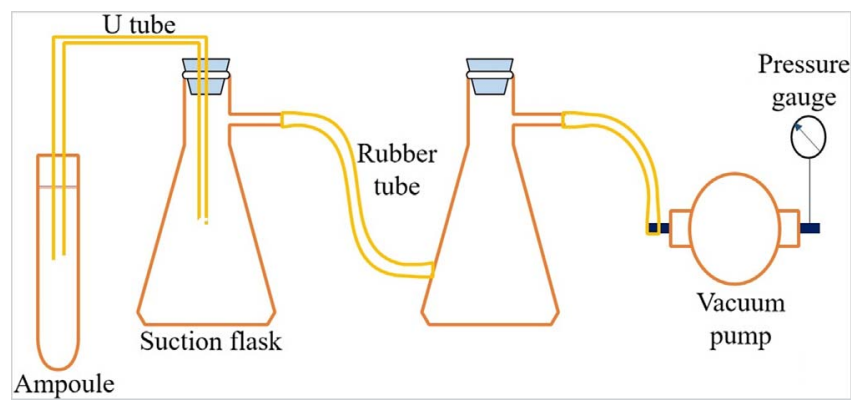

Fig. 1. Schematic diagram of the breakthrough vacuum method.

data is the average of the three results obtained from this experiment.

\subsection{Rheological measurements}

Viscoelastic behaviour of prepared hydrogels (i.e., hydrogels synthesized at $90{ }^{\circ} \mathrm{C}$ ) was evaluated using a compact rheometer with a cone plate sensing system (MCR-52, Anton Paar, and Physica, Austria). The prepared gels were placed into the cone and plate setup after gelation. The frequency sweep test was conducted in the frequency range of $1 \mathrm{~Hz}$ to $100 \mathrm{~Hz}$ at a constant strain of $1 \%$. All the experiments are performed at room temperature $(298 \mathrm{~K})$.

\subsection{Water shut-off performance}

To simulate conventional and nanocomposite hydrogel's plugging capacity in high permeable streaks present in mature oil fields, sandpack flooding experiments were carried out at reservoir conditions $\left(75^{\circ} \mathrm{C}\right)$. The sandpack flooding experiments consist of a Teledyne's ISCO model 500D syringe pump, two cylinders for fluid injection (brine and gelant), a stainless-steel core holder (length $-15 \mathrm{~cm}$ and diameter $-3 \mathrm{~cm}$ ), a pressure gauge and a measuring cylinder for collecting the effluent fluid as shown in Figure 2. The method for sandpack flooding for determining water shut-off was the same as followed by many researchers (Karimi et al., 2014; Zhao et al., 2015). Firstly, the sandpack was prepared by ramming of sand in the core holder so that proper packing can be done. Secondly, brine $(10000 \mathrm{ppm}$ of $\mathrm{NaCl})$ was injected into the sandpack at a constant flow rate of $1 \mathrm{~mL} / \mathrm{min}$ and the permeability of the sandpack (before gel formation) can be determined using the Darcy equation (1) (Singh et al., 2018),

$$
k=\frac{Q \cdot \mu \cdot L}{A \cdot \Delta P},
$$

where, $\mu=$ viscosity of the brine $(\mathrm{cP}), Q=$ flow rate $\left(\mathrm{cm}^{3} / \mathrm{s}\right)$, $L=$ Length of sandpack $(\mathrm{cm}), \Delta P=$ differential pressure (atm), $A=$ cross-sectional area of sandpack $\left(\mathrm{cm}^{2}\right)$ and $k=$ permeability of the sandpack (Darcy).

Thirdly, the 3-4 pore volume of prepared gelant solution of nanocomposite hydrogel (PVP-ZnO:RF) was injected into the sandpack and the effluents were collected into the measuring cylinder (Fig. 2). This collected effluent

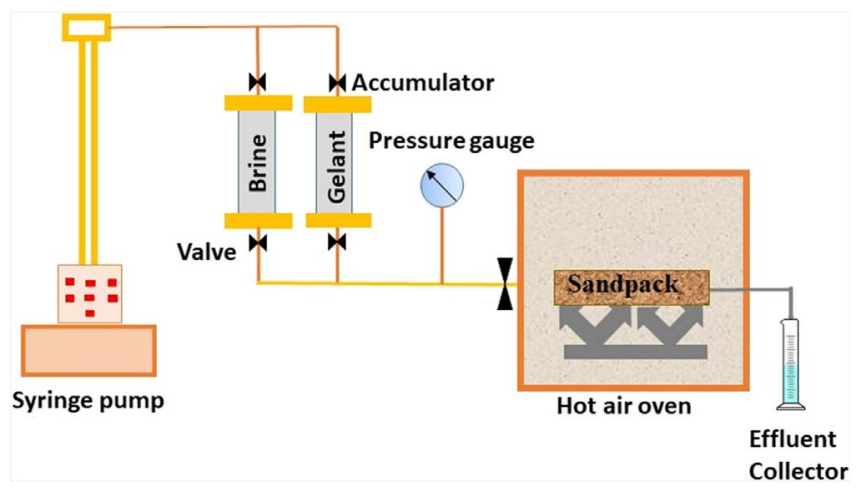

Fig. 2. Schematic experimental set-up for sandpack flooding studies.

was kept in ampules and put in the oven with the sandpack holder. The sandpack was kept approximately 3 times greater than the gelation time of effluent gel samples kept in ampules. After giving enough time to sandpack for complete gelation, brine was again injected into the sandpack and again permeability of sandpack (after gel formation) was calculated. The same procedure was adopted for sandpack flooding using conventional hydrogel (PVP:RF) for comparing against the results obtained during sandpack flooding with nanocomposite hydrogel (PVP-ZnO:RF). The Residual Resistance Factor (RRF) and percentage permeability reduction have reckoned the formulae given in equations (2) and (3), respectively:

$$
\mathrm{RRF}=\frac{\lambda_{w i}}{\lambda_{w a}}=\frac{K_{w i} \mu_{w a}}{K_{w a} \mu_{w i}}
$$

where, $\lambda_{w i}=$ water mobility before gel treatment, $\lambda_{w a}=$ water mobility after gel treatment;

$$
\mathrm{PPR}=\left(1-\frac{K_{w a}}{K_{w i}}\right) \times 100,
$$

$K_{w i}=$ permeability before gel treatment and $K_{w a}=$ permeability after gel treatment.

\section{Results and discussion}

\subsection{UV-Vis spectra and PXRD analysis of $\mathrm{ZnO}$}

The UV-Vis spectrum of the synthesized nanoparticles is depicted in Figure 3a. An absorption peak at $358 \mathrm{~nm}$ represents the ZnO nanofiller's characteristic peak.

The crystalline nature of the material synthesized is determined by using the Powder X-Ray Diffraction (PXRD) analysis. The output obtained through PXRD of synthesized $\mathrm{ZnO}$ nanofiller was compared with the Joint Committee on Powder Diffraction Standards (JCPDS) card and the synthesized nanofiller gave characteristic peaks having $2 \theta$ values $31.79^{\circ}, 34.88^{\circ}, 36.48^{\circ}, 47.63^{\circ}$, $57.03^{\circ}, 63.16^{\circ}$, and $68.18^{\circ}$ which were indexed to $\left(\begin{array}{lll}1 & 0 & 0\end{array}\right)$, (l $\left.0 \begin{array}{ll}0 & 2\end{array}\right),\left(\begin{array}{lll}1 & 0 & 2\end{array}\right),\left(\begin{array}{lll}1 & 1 & 0\end{array}\right),\left(\begin{array}{lll}1 & 0 & 3\end{array}\right)$ planes of the hexagonal phase of the wurtzite crystal structure of $\mathrm{ZnO}$. The data is in 

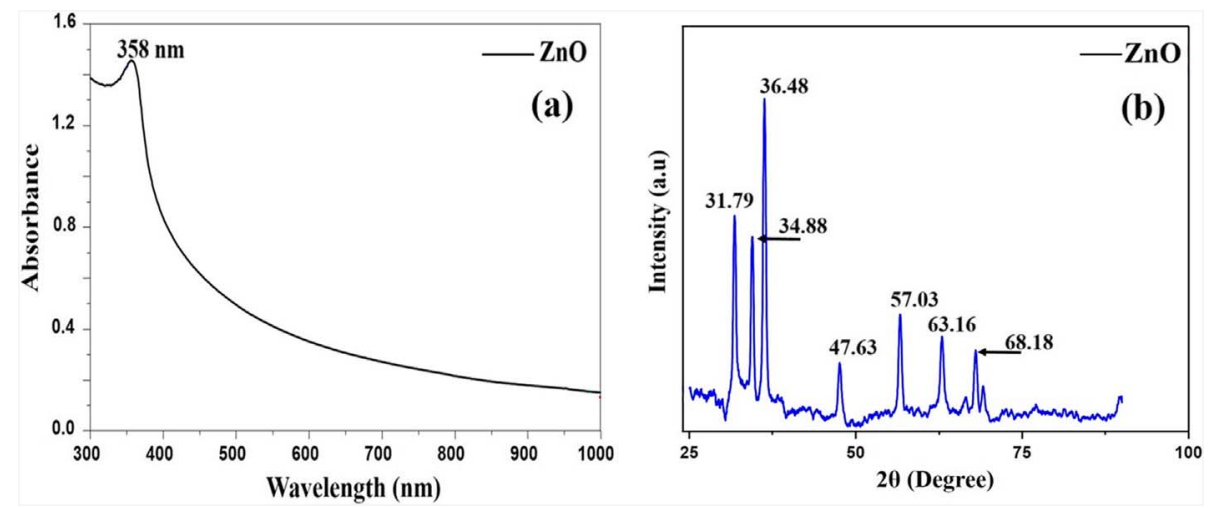

Fig. 3. (a) UV-Vis spectra of pure $\mathrm{ZnO}$, (b) PXRD spectra of pure $\mathrm{ZnO}$ nanofiller.

agreement with the standard JCPDS card 36-145 (Fig. 3b). The average particle size of the $\mathrm{ZnO}$ nanofiller was determined to be $10 \mathrm{~nm}$ using Debye Scherrer's equation (Bokuniaeva and Vorokh, 2019; Langford and Wilson, 1978), which is given as follows:

$$
D=\frac{K \lambda}{B \cos \theta}
$$

where, $D=$ Average size of nanofiller $(\mathrm{ZnO}), K=$ constant (0.9), $\lambda=\mathrm{X}$-ray wavelength in $\AA, B=$ the full width at half maximum of an angular peak in radians, $\theta=$ the Bragg's diffraction angle in radian.

\subsection{Reaction scheme}

Hydrogen bonding between polymer chains and nanoparticles is generally carried out by using a crosslinker. Initially, the polymer solution was prepared along with $\mathrm{ZnO}$. After that, a crosslinker was prepared. Figure 4a represents a reaction between Resorcinol and Formaldehyde (RF) and Figure $4 \mathrm{~b}$ illustrates the condensation reaction of crosslinker formation. Crosslinker (resorcinol-formaldehyde) formation reaction was adapted from Gaca and Sefcik (2013) and Gaca et al. (2017). This reaction is carried out before the crosslinking of PVP and green root synthesized $\mathrm{ZnO}$. After $\mathrm{RF}$ formation, it is expected to increase the interaction between $\mathrm{PVP}$ and $\mathrm{ZnO}$ by the reacting $-\mathrm{OH}$ group of $\mathrm{RF}$ with $\mathrm{C}-\mathrm{O}$ bond of $\mathrm{PVP}$ and $\mathrm{Zn}$ metal of $\mathrm{ZnO}$ following the hydrogen bonding. Hydrogen Bonding between PVP, $\mathrm{RF}$ and $\mathrm{ZnO}$ is illustrated in Figures $4 \mathrm{c}$ and $4 \mathrm{~d}$. $\mathrm{ZnO}$ reacts with both polymer and crosslinker (Jaisai et al., 2012; Mallakpour and Javadpour, 2016). Also, PVP-ZnO:RF interaction is shown in Figure 4d.

\subsection{FTIR analysis}

Interaction between $\mathrm{ZnO}$ and PVP:RF was also examined using FTIR, as depicted in Figure 5. ZnO reacts with the phenyl $-\mathrm{OH}$ group and $-\mathrm{C}-\mathrm{O}$ group of polymer (Gaca and Sefcik, 2013; Michael et al., 2018). PVP:RF and PVP-ZnO:RF (0.5 wt.\% $\mathrm{ZnO}$ ) hydrogels were characterized to confirm the reaction between polymer and crosslinker and the presence of $\mathrm{ZnO}$ nanofiller. As shown in Figure 5,
PVP:RF with and without $\mathrm{ZnO}$ gives a peak $-(\mathrm{C}-\mathrm{N})=$ $1284 \mathrm{~cm}^{-1},-(\mathrm{C}=\mathrm{O})=1639 \mathrm{~cm}^{-1},-(\mathrm{C}-\mathrm{H})=3060 \mathrm{~cm}^{-1}$, and $-(\mathrm{O}-\mathrm{H}) 3321 \mathrm{~cm}^{-1}$ due to hydrogen bonding of PVP with RF. In PVP-ZnO:RF hydrogel, a strong absorption peak was observed at $2342 \mathrm{~cm}^{-1}$; this peak is assigned to be an asymmetrical stretch frequency of $-(\mathrm{O}-\mathrm{C}=\mathrm{O}$ ) (Gaca and Sefcik, 2013). The origin of the band at $642 \mathrm{~cm}^{-1}$ is due to the metal-oxygen bond, which confirms $\mathrm{ZnO}$ nanofiller's presence in PVP-ZnO:RF hydrogel (Gaca et al., 2017).

\subsection{FESEM and EDX analysis}

The FESEM image and EDX data for the $\mathrm{ZnO}$ nanofiller are shown in Figures 6a and 6b. From the EDX graph (Fig. 6b) it can be deduced that the major constituents of synthesized $\mathrm{ZnO}$ nanofiller are $\mathrm{Zn}(79.2 \%)$ and oxygen $(20.48 \%)$. Figures $6 \mathrm{c}$ and $6 \mathrm{~d}$ show the images of the conventional (PVP:RF) and nanocomposite (PVP-ZnO:RF) hydrogels. Dried gel samples were used to evaluate the surface morphologies of hydrogels. Convention gel (PVP:RF) shows a smooth surface Figure 6c. SEM image of nanocomposite gels (PVP-ZnO:RF) as shown in Figure 6d reveals significant alterations in surface morphology due to the presence of $\mathrm{ZnO}$. From pictures, it can be deduced that $\mathrm{ZnO}$ has a considerable impact on the morphology of PVP-ZnO:RF nanocomposite hydrogels. Nanocomposite hydrogel shows a very dense surface, which indicates that $\mathrm{ZnO}$ has significant interaction with PVP \& RF in the synthesis of PVP-ZnO:RF hydrogel (Li et al., 2017).

\subsection{Effect of salinity and temperature on hydrogels}

\subsubsection{Effect of salinity on hydrogels}

The effect of salinity was evaluated on Gelation Time (GT) and Gel Strength (GS) for PVP:RF and PVP-ZnO:RF (0.5 wt.\% $\mathrm{ZnO}$ ) rigid hydrogels (I type gels as per Sydansk code) samples. The effect of salinity was studied using $\mathrm{NaCl}$ and $\mathrm{CaCl}_{2}$ (0.25-1.0 wt.\%) salts solution keeping it at the temperature of $90{ }^{\circ} \mathrm{C}$. It was observed that as the concentration of salts $\left(\mathrm{NaCl}\right.$ and $\left.\mathrm{CaCl}_{2}\right)$ increases, it decreases the gel strength whereas increases the gelation time (Fig. 7). As the sodium ion concentration increases and it accumulates around the polyvinyl pyrrolidone carbonyl 
Reaction between Resorcinol and Formaldehyde (RF)

(a)

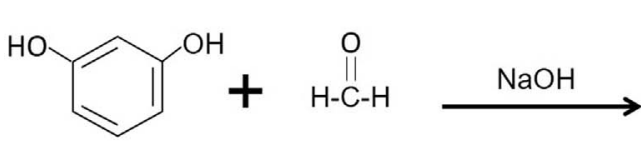

Resorcinol Formaldehyde

Condensation reaction between $\mathrm{RF}$

$2 \mathrm{~m}$

$2 n$<smiles>OCc1cc(CO)c(CO)cc1O</smiles><smiles>OCc1cc(CO)c(CO)cc1O</smiles><smiles>OCc1cc(CO)c(O)cc1O</smiles>

(m)

(n)

Hydrogen bonding scheme in the final mixture of PVP:RF

(c)<smiles>O=C1CCCN1C([AlH2])I</smiles><smiles>CCc1c(O)c(CO)c(CO)c(CO)c1CO</smiles>

Resorcinol-formaldehyde resin

PVP:RF

Fig. 4. (a) Reaction between Resorcinol-Formaldehyde (RF), (b) condensation reaction of RF, (c) hydrogen bonding scheme of PVP:RF, (d) PVP-ZnO, and (e) PVP-ZnO:RF. 
Hydrogen bonding scheme of PVP-ZnO

(d)

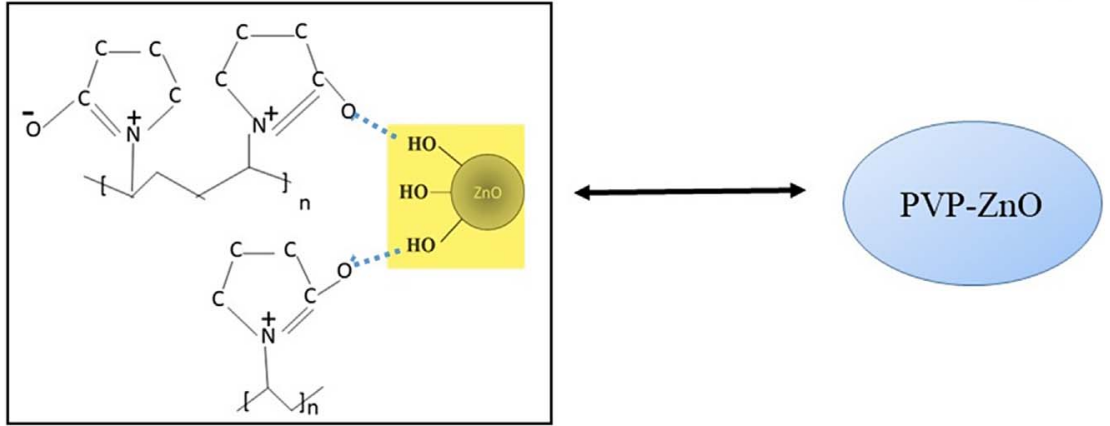

Hydrogen bonding scheme in the final mixture of PVP-ZnO:RF

(e)

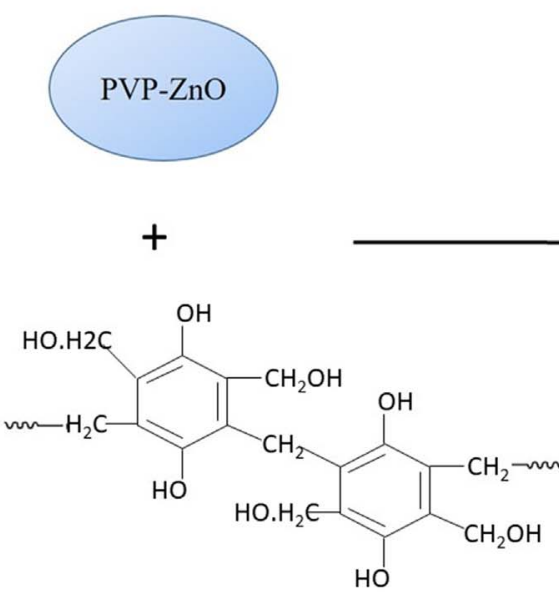

Resorcinol-formaldehyde resin

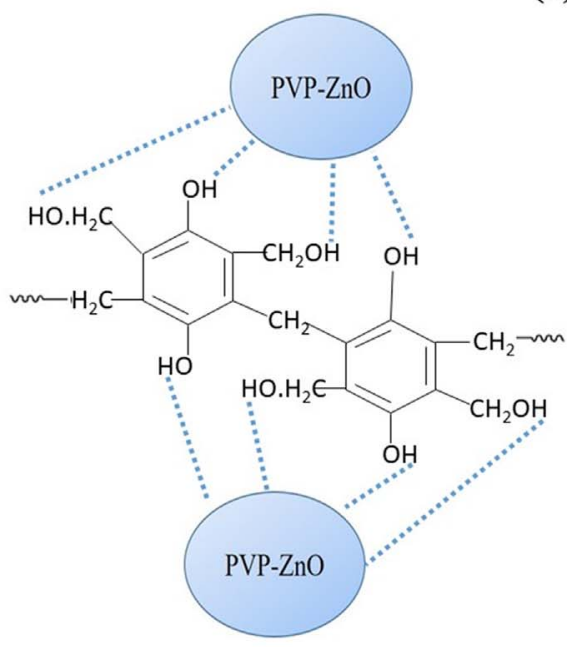

PVP-ZnO:RF

Fig. 4. Continued.

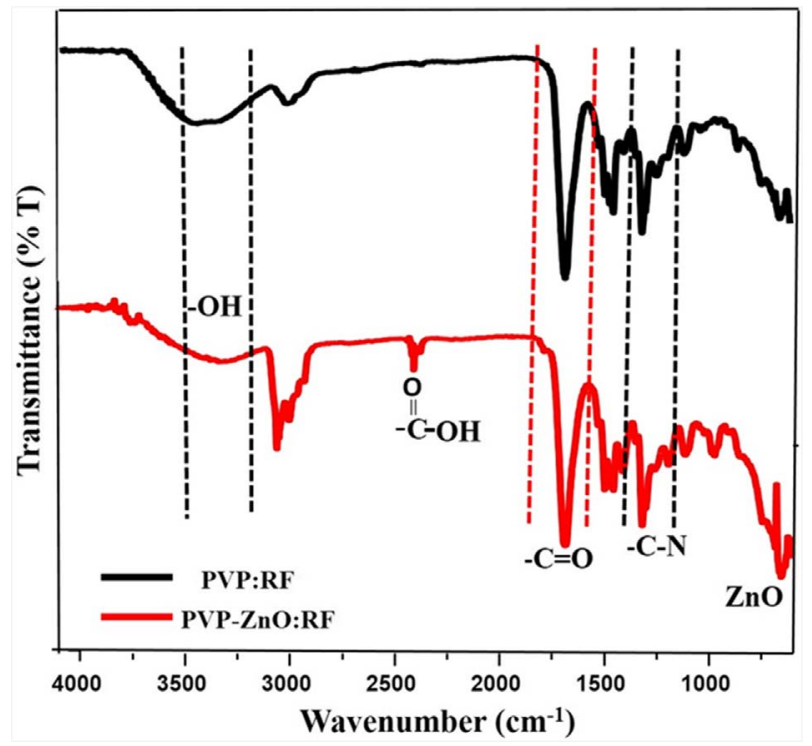

Fig. 5. FTIR spectrum of conventional (PVP:RF) and nanocomposite (PVP-ZnO:RF) hydrogels. ring. Double layer formation happens due to the presence of both anions and cations. Double layer formation contributes to the contraction of polymer chains. There are adverse effects on the gel strength from the presence of divalent cation (calcium). The divalent cation can also cause the deposition of the polymer (Dai et al., 2014; Li et al., 2013).

\subsubsection{Effect of temperature on hydrogels}

Gelation temperature also plays a vital role in gel formation and also affects the gel strength of gel samples. The gelation time of gels can be decreased by a rise in the temperature or vice versa (Park et al., 2020). PVP:RF and PVP-ZnO:RF $(0.5$ wt.\% $\mathrm{ZnO})$ hydrogels were investigated from 50 to $90{ }^{\circ} \mathrm{C}$. Figure 8 shows that gelation time decreases with the temperature rise. The gelling time for the conventional gel system was recorded to be 22 hours at $50{ }^{\circ} \mathrm{C}$, whereas the gelation time of nanocomposite gel was noted to be 18 hours at the same temperature. Gelling time sharply decreased to 10 hours and 8 hours at $90{ }^{\circ} \mathrm{C}$ for PVP:RF and PVP-ZnO:RF hydrogels respectively. Due to the interaction between polymer and crosslinker molecules, inner 

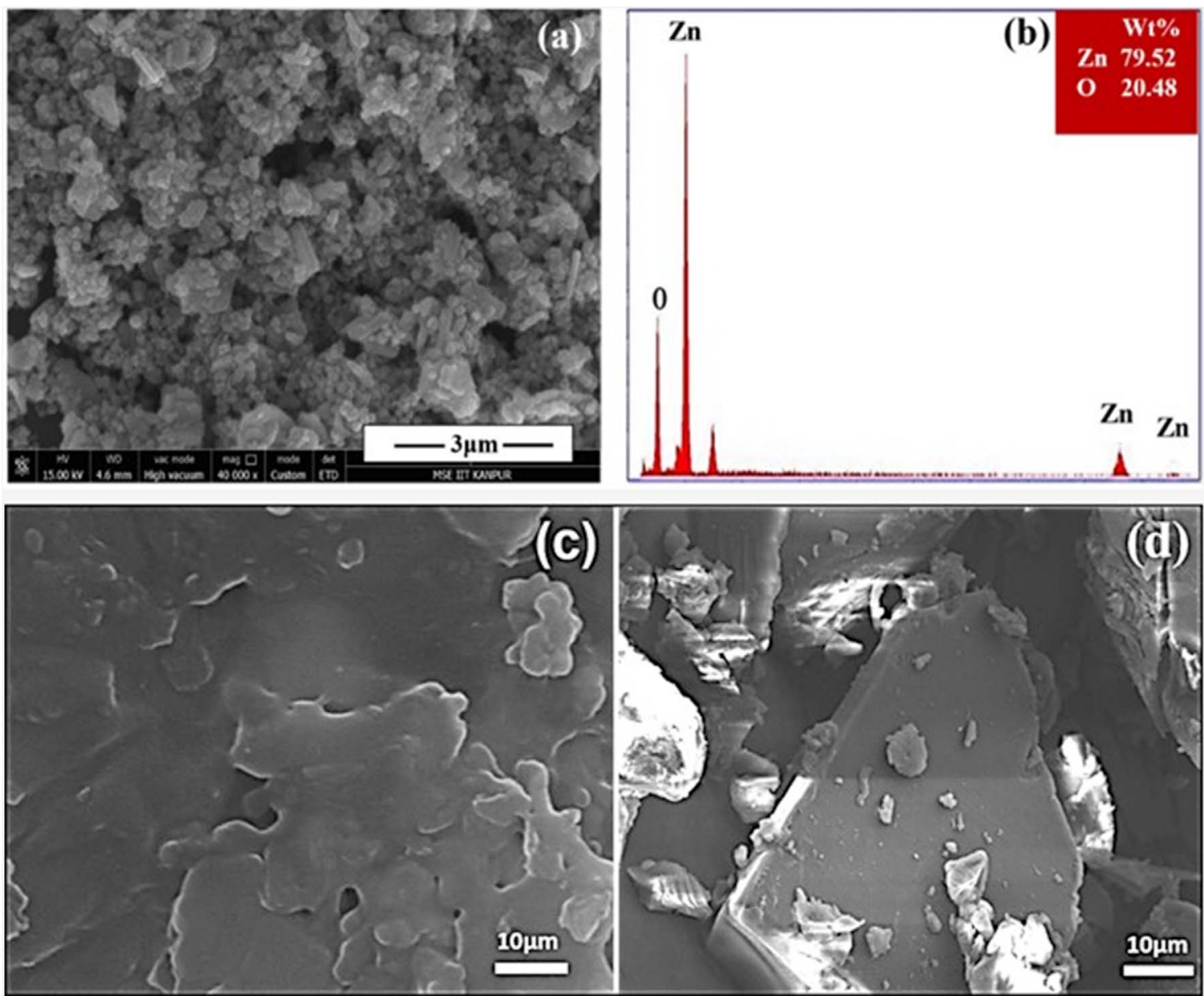

Fig. 6. (a) SEM image of $\mathrm{ZnO}$ nanofiller, (b) EDX spectrum of ZnO. SEM micrographs of investigated gel systems at $\times 10000$, (c) PVP:RF, (d) PVP-ZnO:RF (0.5 wt.\% ZnO).
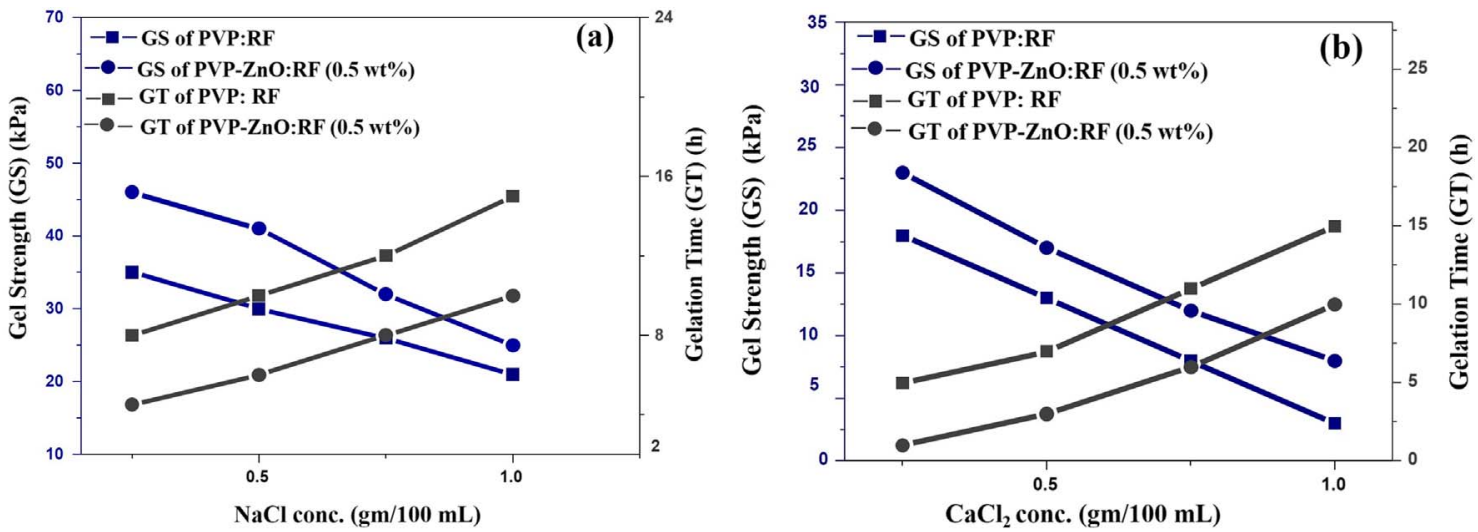

Fig. 7. Effect of (a) $\mathrm{NaCl}$ and (b) $\mathrm{CaCl}_{2}$ salt on Gel Strength (GS) and Gelation Time (GT) at $90{ }^{\circ} \mathrm{C}$.

particle forces also increase; therefore, gel strength also increases at high temperatures. At $50{ }^{\circ} \mathrm{C}$ gel strength was found to be $22.5 \mathrm{KPa}$ and $25 \mathrm{KPa}$ whereas at $90{ }^{\circ} \mathrm{C}$ it was found to be $26 \mathrm{KPa}$ and $29 \mathrm{KPa}$ for PVP:RF and
PVP-ZnO:RF hydrogel systems respectively. The results elucidate that nanocomposite hydrogel (PVP-ZnO:RF) has better gel strength with less gelation time in comparison to that conventional hydrogel (PVP:RF). This may be due 


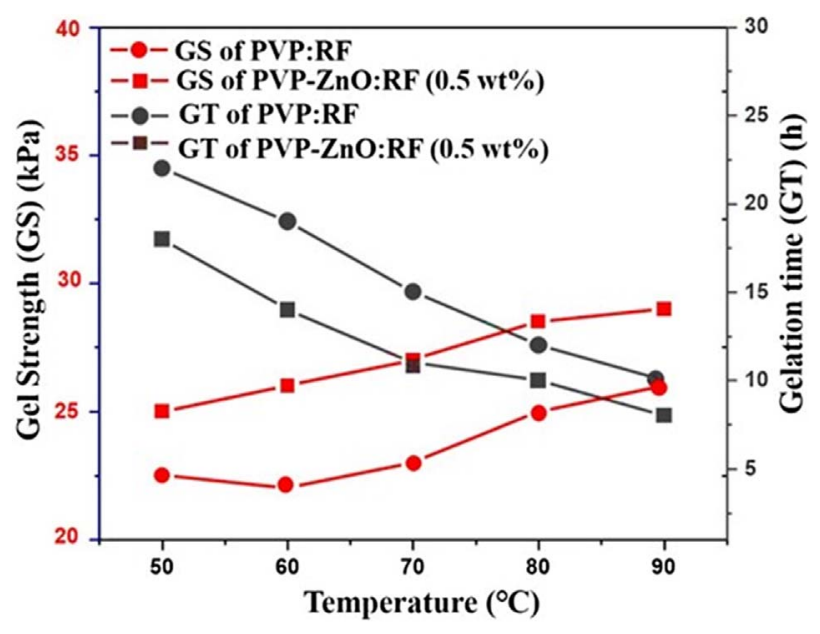

Fig. 8. Effect of temperature on gel strength and gelation time on conventional (PVP:RF) and nanocomposite (PVP-ZnO:RF) hydrogels.

to as following hypothesis: (i) it has been demonstrated that as temperature rises, the curling degree of the polymer molecular decreases, resulting in a shortening of the intermolecular distance, and the crosslinking agent i.e., twisting of polymer chains which are reduced with the increase of temperature, resulting in a reduction of the intermolecular distance of gel matrix. Therefore, gelation time is reduced and gel strength is enhanced at higher temperatures and vice versa (Zhang et al., 2017). (ii) One more explanation for this finding may be attributed to the fact that increasing the thermal motion of molecules in solution with temperature accelerates the intertwining reaction between polymer molecules and crosslinkers, increasing their ability to agglomerate. Thus, it enhances the gel strength and reduces gelation time and vice-versa (Jia et al., 2016; Zhao et al., 2013).

The relationship between Gelation Time (GT) and Temperature $(T)$ is explicated by the Arrhenius-type equation (Al-Muntasheri et al., 2008; Zhao et al., 2013):

$$
\mathrm{GT}=M \mathrm{e}^{\frac{E_{a}}{R T}}
$$

where, GT $=$ Gelation Time $(\mathrm{h})$ and $M=$ frequency factor (h), $E_{a}=$ activation energy $(\mathrm{KJ} / \mathrm{mol}), R=$ gas constant $(\mathrm{KJ} / \mathrm{mol} \mathrm{K}$ ) and $T=$ Absolute temperature $(\mathrm{K})$.

Equation (5) can be again modified as follows:

$$
\ln \mathrm{GT}=\frac{E_{a}}{R T}+\ln M .
$$

As we can see from equation (6), there is a linear relationship between ln GT and the inverse of temperature $(1 / T)$. It is depicted in Figures $9 \mathrm{a}$ and $9 \mathrm{~b}$. As calculated from the slopes of graphs (Figs. 9a and 9b), the activation energy was obtained to be 19.786 and $19.098 \mathrm{KJ} / \mathrm{mol}$ for PVP: RF and PVP-ZnO:RF hydrogels. Results from the Arrhenius-type plot indicated that in nanocomposite (PVP-ZnO:RF) hydrogel lower activation energy is required in comparison to conventional (PVP:RF) hydrogel to proceed with the gelation reaction. Hence, it leads to a shorter gelation time of nanocomposite (PVP-ZnO:RF) hydrogel gel at higher temperatures (Zhao et al., 2013).

\subsection{DSC analysis}

The thermal stability of a material can be evaluated using DSC analysis. In the present research, PVP:RF and PVP$\mathrm{ZnO}: \mathrm{RF}$ hydrogels were characterized using this technique. The evaluation of degradation enthalpy (i.e., the amount of energy required to break the bonds between polymer and crosslinker) helps in determining the bond strength of the interaction between polymer and crosslinker in a crosslinked hydrogel. The stronger the bond strength, the more endothermic energy is consumed to collapse bonds of hydrogel systems. In addition to this, DSC analysis helps to obtain degradation temperature (i.e., the temperature at which the crosslinked chains of hydrogel systems start to disintegrate). At this temperature, PVP chains' mobility was observed to increase (Asloun et al., 1989).

The strength of the hydrogels is found to be dependent on various direct and indirect interactions occurring within the gel systems (Chua et al., 2007). There are numerous kinds of direct and indirect interactions possible in hydrogels. Direct interactions can occur between the PVP, RF and ZnO, which includes PVP-PVP, PVP-RF, $\mathrm{RF}-\mathrm{RF}$, or $\mathrm{PVP}-\mathrm{ZnO}-\mathrm{RF}$ interactions. Indirect interactions transpire due to the presence of water content in hydrogels. From Figure 10 it can be seen that there are three types of water (i) Strong Bound Water (SBW), (ii) Weak Bound Water (WBW), and (iii) Free Water (FW). SBW is non-freezable water and FW is freezable water but WBW can be present as both (Gun'ko et al., 2017). SBW leads to strong indirect interactions in gels because it is directly associated with PVP-ZnO:RF and FW lead to weak interactions between water molecules. The free water is referred to as the water, which gets physically absorbed by the gel system and is bonded to each other via hydrogen bond (weak indirect interaction). On the other hand, the water, which is chemically bound to the polymer surface, is known to be as bound water (strong indirect interaction) as shown in Figure 10 (Liu et al., 2017; Michael et al., 2018).

From the endothermic peak in the temperature range of $0-10{ }^{\circ} \mathrm{C}$, the amount of free water can be calculated as in Figure 11 using the following equations (Liu et al., 2017):

$$
\mathrm{W}_{f}=\Delta H / \Delta H^{\circ},
$$

where, $W_{f}=$ weight fraction of free water; $\Delta H=$ the enthalpy required for free water in hydrogels and $\Delta H^{\circ}=$ melting enthalpy value of free water $(333.5 \mathrm{~J} / \mathrm{g})$;

$$
W_{b}=1-W_{f}
$$

and $W_{b}=$ weight fraction of bound water (Liu et al., 2017).

Moreover, higher degradation enthalpy suggests a stronger bond between PVP and $\mathrm{ZnO}$ nanofiller. Figure 11 shows DSC curves of the PVP-ZnO:RF nanocomposites (0.2 wt.\% - 1 wt.\%) as well as conventional PVP:RF 

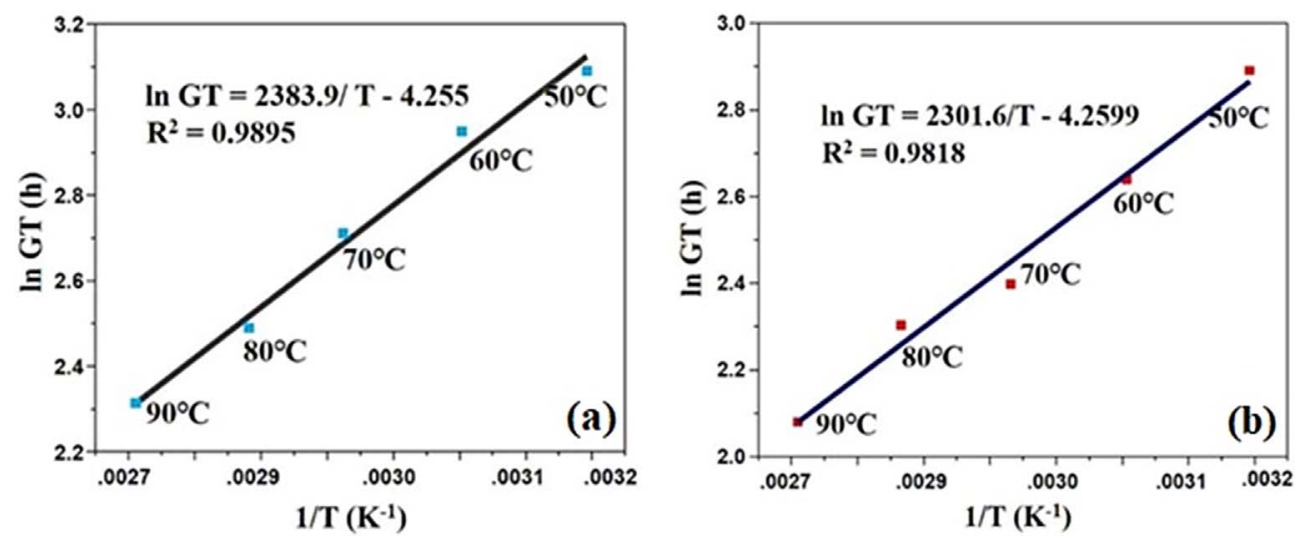

Fig. 9. Arrhenius type graph of (a) conventional (PVP:RF) and (b) nanocomposite (PVP-ZnO:RF; (0.5 wt.\% ZnO) hydrogels.

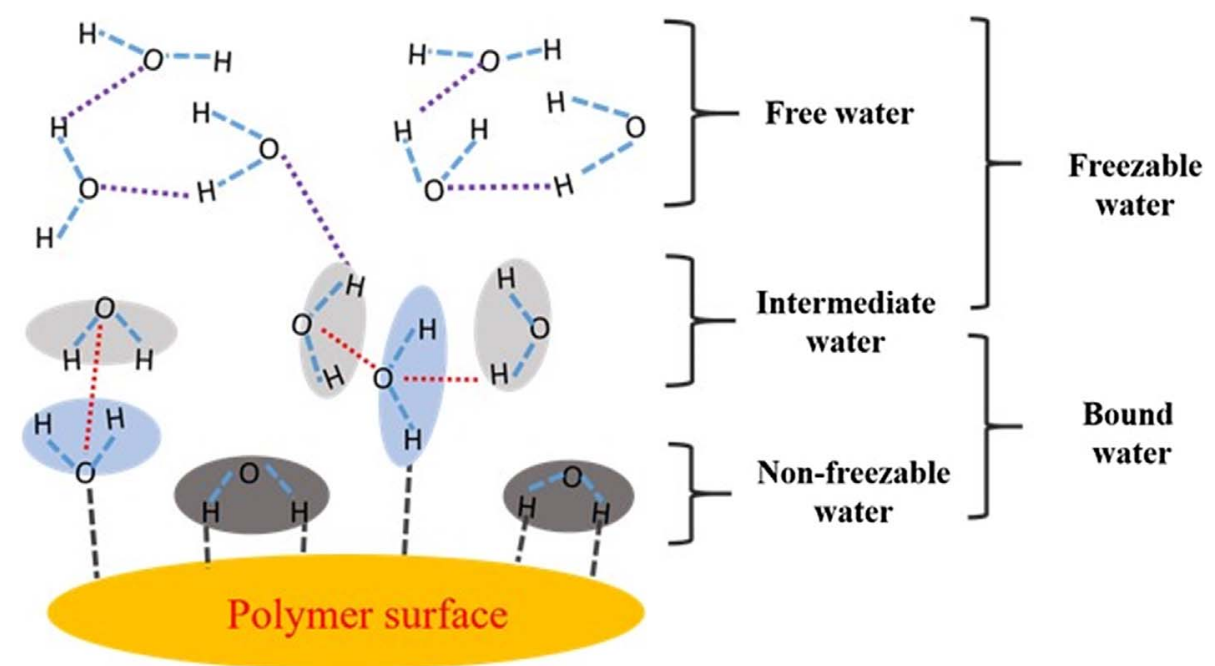

Fig. 10. Schematic representation of free water (weak indirect interaction) and bound water (strong indirect interaction) interactions in hydrogels (Michael et al., 2018; Reena et al., 2020).

hydrogel alone. PVP:RF and PVP-ZnO:RF (0.2 wt.\% and 0.5 wt.\%) were rigid gels gel (I type gels as per Sydansk code). PVP-ZnO:RF (0.8 wt.\% and 1 wt.\%) gels were moderately deformable non-flowing gel ( $\mathrm{G}$ type gels as per Sydansk code).

From Figures 11a to 11e, two peaks were observed in the DSC profiles of the hydrogel systems.

The first peak of the profile represents the presence of free water in the hydrogel systems while the second peak portrays the degradation temperature $\left(T_{\mathrm{deg}}\right)$ of the hydrogels. It was deduced that a lower amount of free water was attached to the surface of PVP:RF $0.5 \mathrm{wt} . \% \mathrm{ZnO}$ hydrogel system in comparison to PVP:RF 1 wt.\% $\mathrm{ZnO}$ hydrogel system. Moreover, in a nutshell, from the graphs (Fig. 11), it can be depicted that with the increase in $\mathrm{ZnO}$ nanofiller concentration, the degradation temperature exhibits an increasing trend (i.e., up to $0.5 \mathrm{wt} . \% \mathrm{ZnO}$ concentration) afterward the addition of $\mathrm{ZnO}$ nanofiller shows a decreasing trend of the degradation temperature. It may be due to the shorter length of polymer chains in the hydrogel network or agglomeration of $\mathrm{ZnO}$ filler which assisted the polymer molecules to slide over each other at higher $\mathrm{ZnO}$ concentrations easily. Low degradation temperatures of hydrogels having a high concentration of $\mathrm{ZnO}$ nanofiller may be apparent due to the multiple types of interactions such as $\mathrm{ZnO}$ nanofiller-PVP and nanofillernanofiller interaction occurring within the gel network (El-Mekawy and Jassas, 2017). Thus, it can be deduced that PVP-ZnO:RF hydrogels with 0.5 wt.\% of $\mathrm{ZnO}$ are thermally more stable among other PVP-ZnO:RF hydrogels.

\subsection{Rheological measurements of hydrogels}

The interaction between polymer and nanofiller can also impact the viscoelastic properties of the hydrogels. 

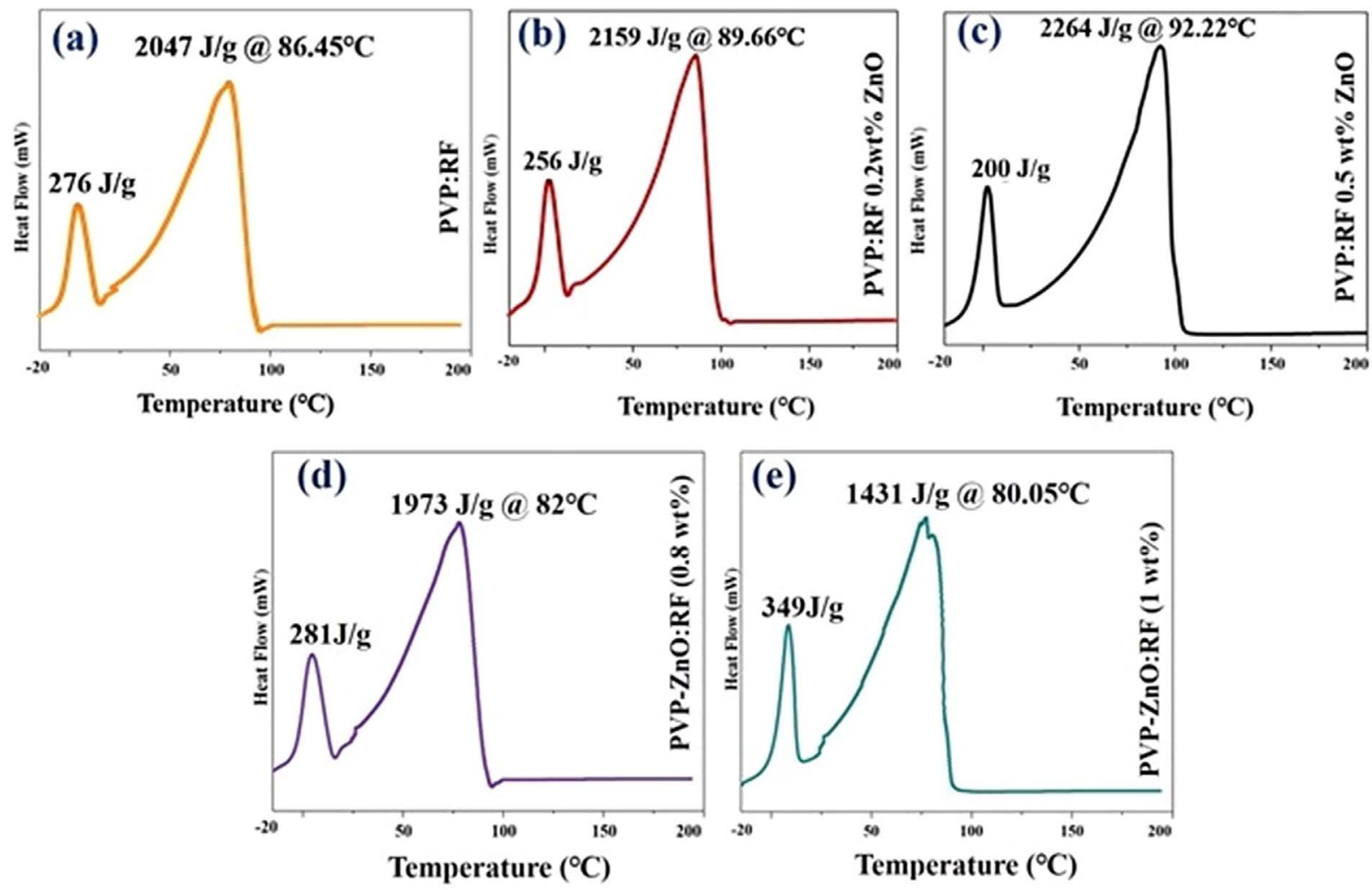

Fig. 11. DSC thermographs for PVP-ZnO:RF (0-1 wt.\% $\mathrm{ZnO})$.
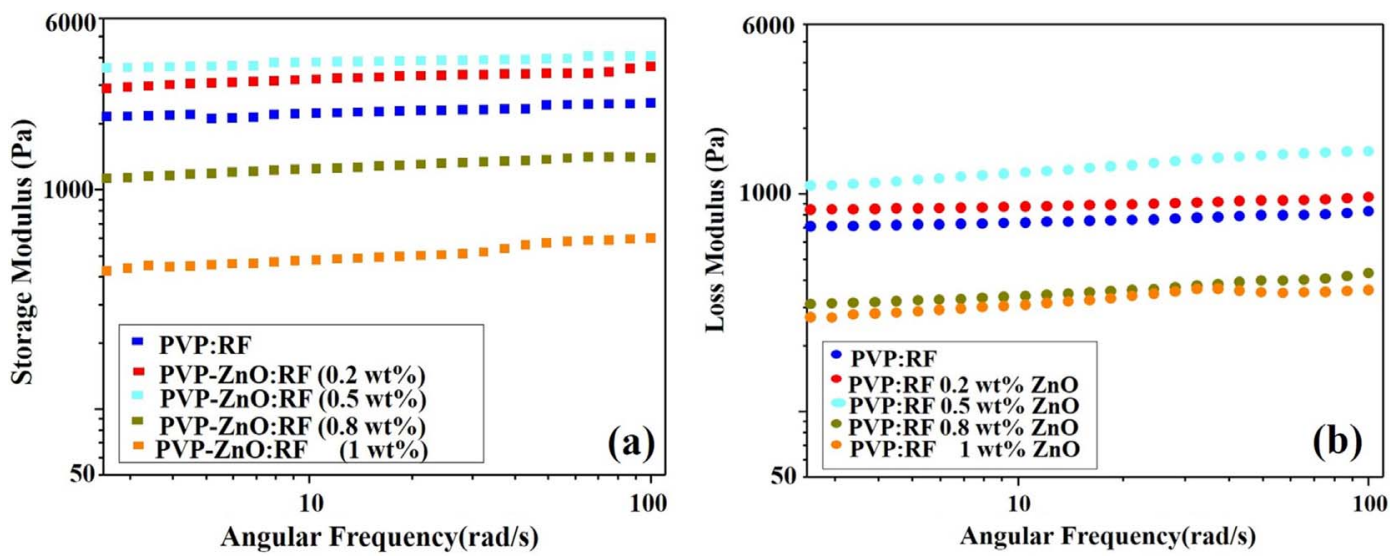

Fig. 12. Frequency sweep test, (a) storage modulus, (b) loss modulus for PVP-ZnO:RF (0-1 wt.\%) $(T=298 \mathrm{~K})$.

The strength of the gels can be determined through their rheological properties. These properties include dynamic moduli (i.e., storage modulus $\left(G^{\prime}\right)$ and loss modulus $\left(G^{\prime \prime}\right)$. Solid like behaviour of gel or energy stored by gels which can be recovered are represented by storage modulus $\left(G^{\prime}\right)$ while liquid-like behaviour of gel or dissipated energy and cannot be recovered are represented by loss modulus $\left(G^{\prime \prime}\right)$. The ratio of storage and loss modulus (i.e., $G^{\prime} / G^{\prime \prime}$ ) is measured as gel strength of hydrogels (Liu et al., 2017). The higher ratio shows solid like behaviour while the lower ratio leads to the liquid-like behaviour of hydrogels..

The ZnO nanofiller's effect on the rheological behaviour of hydrogels was determined by conducting the frequency sweep test. It was observed from the result that the elastic modulus values $\left(G^{\prime}\right)$ are higher than loss modulus $\left(G^{\prime \prime}\right)$ as 
Table 2. Sandpack study results for PVP:RF and PVP-ZnO:RF.

\begin{tabular}{llcc}
\hline SL No. & \multicolumn{1}{c}{ Parameters } & \multicolumn{2}{c}{ Observed values for hydrogel systems } \\
\cline { 3 - 4 } & & PVP:RF & PVP-ZnO:RF (0.5 wt.\%) \\
\hline 1. & Porosity of sandpack & $27 \%$ & $28 \%$ \\
2. & Intestinal velocity (ft/day) & 24.7543 & 23.8703 \\
3. & Initial permeability before gel injection (Darcy) & 3.82 & 4.26 \\
4. & Post gelation permeability after gel injection (Darcy) & 0.30 & 0.13 \\
5. & Percentage Permeability Reduction (PPR) \% & 92 & 97 \\
6. & Residual Resistant Factor (RRF) & 12.71 & 31.31 \\
\hline
\end{tabular}

shown in Figures $12 \mathrm{a}$ and $12 \mathrm{~b}$ which indicates that the value of elastic modulus is dominating over the value of viscous modulus. Thus, these results suggest a solid or rubber-like behaviour of hydrogel systems. Moreover, there is also no crossover or gel point in the entire frequency range (i.e., 1-100 Hz) which recommends that hydrogel retains its rubber-like behaviour or solid-like behaviour in the whole frequency range. The graphs (Figs. 12a and 12b) show nanofiller's effect on the dynamic moduli of hydrogels. The value of storage modulus $\left(G^{\prime}\right)$ and loss modulus $\left(G^{\prime \prime}\right)$ shows an increase in value with the rise in $\mathrm{ZnO}$ concentrations (i.e., $0.2-0.5 \mathrm{wt} . \%$ ) whereas the respective values diminish on further increasing the $\mathrm{ZnO}$ concentrations (0.8-1 wt.\%). The decrease in the dynamic moduli at higher concentrations may be due to the agglomeration of $\mathrm{ZnO}$ nanofiller (Arsad et al., 2013). From obtained results, nanocomposite hydrogel (PVP-ZnO:RF) showed higher elastic and loss modulus than conventional gel (PVP:RF) if the $\mathrm{ZnO}$ concentration is not too high (i.e., less than 0.8 wt.\%).

\subsection{Water shut-off performance}

To simulate the higher permeable zones, present in mature oil fields sandpack experiments were conducted using both the hydrogels, i.e., conventional hydrogel (PVP:RF) and nanocomposite hydrogel (PVP-ZnO:RF; 0.5 wt.\%). The experimental data of the sandpack studies are shown in Table 2.

The value of injection flow rate was maintained at $1 \mathrm{ml} / \mathrm{min}$ while testing both the hydrogel systems (i.e., PVP:RF and PVP-ZnO:RF). The respective porosity of both sandpack (i.e., PVP:RF and PVP-ZnO:RF) are found to be $27 \%$ and $28 \%$. The corresponding interstitial velocity during the coreflood test is $24.7543 \mathrm{ft} /$ day (or $0.3144 \mathrm{~m} / \mathrm{h}$ ) and $23.8703 \mathrm{ft} /$ day (or $0.30315 \mathrm{~m} / \mathrm{h}$ ) for PVP:RF and PVP-ZnO:RF hydrogels. The initial permeability of the sandpack using brine was found to be 3.82 and 4.26 Darcy respectively for PVP:RF and PVP-ZnO:RF gel systems. After that, the gelant solution was injected into the sandpack and was kept in an oven at a temperature of $75{ }^{\circ} \mathrm{C}$ for 3 days to ensure complete gel formation. After gelation, the absolute permeability to brine was measured as 0.30 and 0.13 Darcy respectively for PVP:RF and PVP-ZnO:

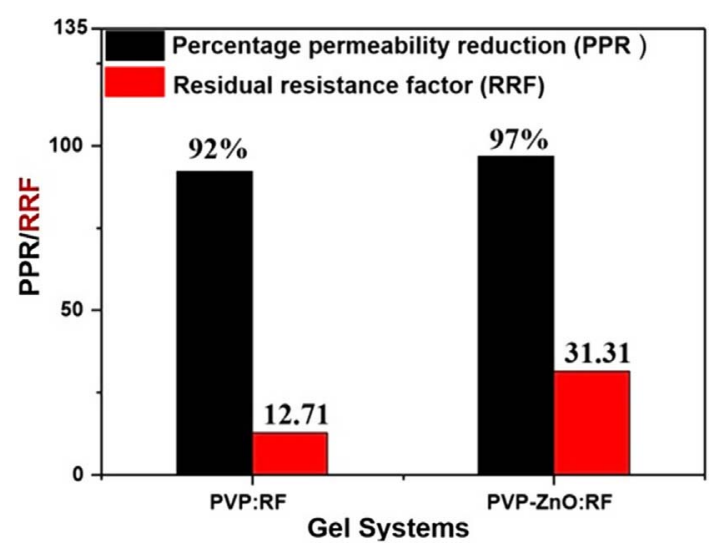

Fig. 13. Percentage Permeability Reduction (PPR) and the Residual Resistance Factor (RRF) of PVP:RF and PVP-ZnO: $\mathrm{RF}$ hydrogels (at $343 \mathrm{~K}$ or $75^{\circ} \mathrm{C}$ ).

RF hydrogel systems. Thus, Percentage Permeability Reductions (PPR) were $97 \%$ and $92 \%$, respectively for conventional gels (PVP:RF) and nanocomposite (PVP-ZnO: $\mathrm{RF}$ ) hydrogel systems (Fig. 13). Also, it was found that Residual Resistance Factors (RRF) were 31.31 and 12.71 for nanocomposite and conventional hydrogels respectively (Fig. 13). The higher value of PPR and RRF in nanocomposite hydrogel (PVP-ZnO:RF) compared to conventional hydrogel (PVP:RF) shows that $\mathrm{ZnO}$ nanofiller's use has enhanced its capability to reduce water in heterogeneous layer present in mature oil fields.

The purposed mechanism for water shut-off due to the placement of nanocomposite hydrogel (PVP-ZnO:RF) in the high permeable zone is elucidated in Figures 14a-14c.

In Figure 14a due to the presence of a high permeable zone flooded water is mainly produced leaving the crude oil unswept in low permeable zones. The placement of nanocomposite hydrogel (PVP-ZnO:RF) restricts the flooded water to flow through the high permeable zones (Fig. 14b). Due to the obstruction created by the placement of nanocomposite hydrogel, flooded water is compelled to sweep the crude oil present in low permeable zones (Fig. 14c) which in turn results in incremental oil recovery. 


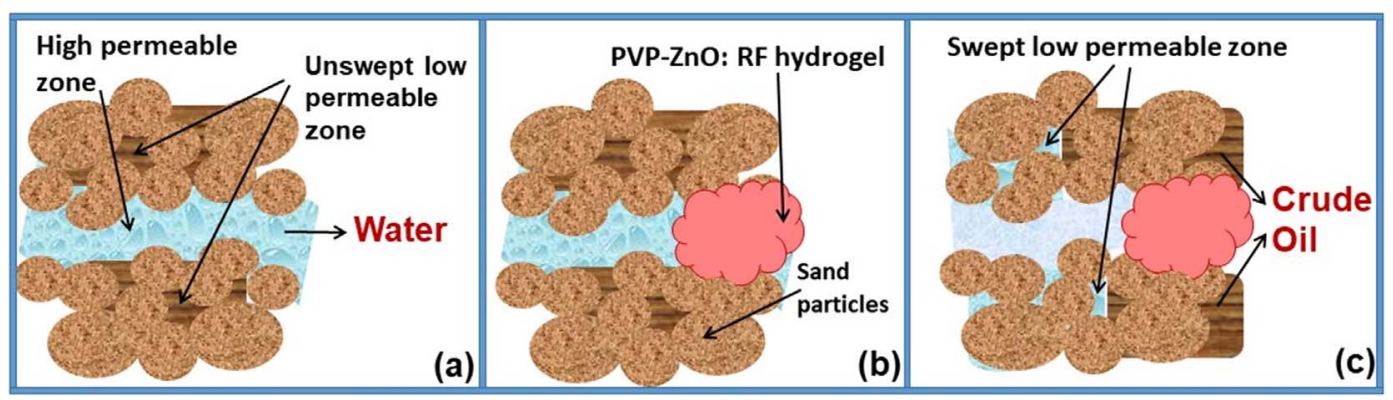

Fig. 14. Schematic of excessive water production problem and water shut-off mechanism, (a) a high permeable zone due to long term waterflooding produces mainly water, (b) gel treatment was done from a producer well, (c) water sweeps untouched low permeable zones after hydrogel placement in the high permeable zone for incremental oil recovery.

\section{Conclusion}

The following conclusions were derived from the studies:

1. Zinc Oxide $(\mathrm{ZnO})$ was successfully prepared by biosynthesis of plant extract from Moringa oleifera leaves and its average particle size was found to be $10 \mathrm{~nm}$.

2. Convention hydrogel (PVP:RF) and zinc oxide reinforced nanocomposite hydrogel (PVP-ZnO:RF) were successfully prepared.

3. From the FTIR analysis, a peak at $642 \mathrm{~cm}^{-1}$ was observed which signifies the presence of metal-oxygen bond, thus, confirming the presence of $\mathrm{ZnO}$ nanofiller in the nanocomposite hydrogel (PVP-ZnO:RF) matrix.

4. FESEM images revealed that the nanocomposite hydrogel (PVP-ZnO:RF) has a significant alteration in surface morphology, which suggests the $\mathrm{ZnO}$ nanofiller's presence in the hydrogel.

5. Gel strength of hydrogels (i.e., conventional (PVP: $\mathrm{RF}$ ) and nanocomposite (PVP-ZnO:RF)) decreases with the increase in salinity due to the rise in salts concentrations $\left(\mathrm{NaCl}\right.$ and $\left.\mathrm{CaCl}_{2}\right)$. However, reinforcement of $\mathrm{ZnO}$ nanofiller leads to a decrease in gelation time but an increase in gel strength at a specific salt concentration.

6. Both conventional (PVP:RF) and nanocomposite hydrogel (PVP-ZnO:RF) demonstrate a decrease in gelation time and an increase in gel strength with the temperature rise. Moreover, the reinforcement of $\mathrm{ZnO}$ nanofiller results in a decrease in gelation time and an increase in gel strength at a higher temperature in hydrogel systems.

7. DSC analysis illustrates that $\mathrm{ZnO}$ nanofiller (at lower concentration i.e., 0.2-0.5 wt.\%) enhances nanocomposite hydrogel's thermal stability. The addition of higher concertation of $\mathrm{ZnO}$ nanofiller leads to a decrease in thermal stability $(0.8-1 \mathrm{wt} . \%)$. The optimum temperature was found to be around $92{ }^{\circ} \mathrm{C}$ up to which the nanocomposite (PVP-ZnO:RF; 0.5 wt.\% of $\mathrm{ZnO}$ ) hydrogel is thermally stable.

8. The rheological studies depicted that the prepared hydrogels i.e., conventional (PVP:RF) and nanocomposite (PVP-ZnO:RF) exhibit viscoelastic nature. Reinforcement of $\mathrm{ZnO}$ (at lower concentration i.e., $0.2-0.5$ wt.\%) in the PVP-ZnO:RF nanocomposite hydrogel increases its dynamic moduli (i.e., storage modulus as well as loss modulus); afterward, further reinforcement leads to a decrease in dynamic moduli. The optimum value of dynamic moduli of PVP$\mathrm{ZnO}: \mathrm{RF}$ hydrogel was found at $0.5 \mathrm{wt} . \%$ of $\mathrm{ZnO}$.

9. Sandpack studies determined that Percentage Permeability Reduction (PPR) and a Residual Resistance Factor (RRF) are $97 \%$ and 31.31 respectively for nanocomposite hydrogel (PVP-ZnO:RF) which are higher than that of conventional (PVP:RF) hydrogel. Thus, reinforcement of biosynthesized - $\mathrm{ZnO}$ nanofiller has enhanced the water shut-off performance of PVP-ZnO:RF hydrogel for heterogeneous layer present in mature hydrocarbon fields.

\section{References}

Aalaie J., Vasheghani-Farahani E., Rahmatpour A., Semsarzadeh M.A. (2008) Effect of montmorillonite on gelation and swelling behavior of sulfonated polyacrylamide nanocomposite hydrogels in electrolyte solutions, Eur. Polym. J. 44, 2024-2031.

Abdulbaki M., Huh C., Sepehrnoori K., Delshad M., Varavei A. (2014) A critical review on use of polymer microgels for conformance control purposes, J. Pet. Sci. Eng. 122, $741-753$.

Adewunmi A.A., Ismail S., Sultan A.S. (2018) Crosslinked polyacrylamide composite hydrogels impregnated with fly ash: Synthesis, characterization and their application as fractures sealant for high water producing zones in oil and gas wells, $J$. Polym. Environ. 26, 3294-3306.

Al-Anazi H.A., Sharma M.M. (2002) Use of a pH sensitive polymer for conformance control, in: International Symposium and Exhibition on Formation Damage Control, February 20-21, 2002, Lafayette, Louisiana.

Al-Muntasheri G.A., Nasr-El-Din H.A., Hussein I.A. (2007) A rheological investigation of a high temperature organic gel used for water shut-off treatments, J. Pet. Sci. Eng. 59, 73-83.

Al-Muntasheri G.A., Nasr-El-Din H.A., Zitha P.L.J. (2008) Gelation kinetics and performance evaluation of an organically crosslinked gel at high temperature and pressure, SPE J. 13, 337-345. 
Arsad A., Rahmat A.R., Hassan A., Mokhtar M., Dali S.N.M. (2013) Flow characteristics and dynamic behavior of polyamide 6/acrylonitile butadiene styrene (PA6/ABS) blends, Int. J. Polym. Mater. Polym. Biomater. 62, 209-214.

Asloun E.M., Nardin M., Schultz J. (1989) Stress transfer in single-fibre composites: Effect of adhesion, elastic modulus of fibre and matrix, and polymer chain mobility, J. Mater. Sci. 24, 1835-1844.

Bailey B., Crabtree M., Tyrie J., Elphick J., Kuchuk F., Romano C., Roodhart L. (2000) Water control, Oilfield Rev. 12, 30-51.

Bokuniaeva A.O., Vorokh A.S. (2019) Estimation of particle size using the Debye equation and the Scherrer formula for polyphasic $\mathrm{TiO}_{2}$ powder, in, J. Phys. Conf. Ser., 1410, 012057.

Chen L., Wang J., Yu L., Zhang Q., Fu M., Zhao Z., Zuo J. (2018) Experimental investigation on the nanosilica-reinforcing polyacrylamide/polyethylenimine hydrogel for water shutoff treatment, Energy Fuels 32, 6650-6656.

Chua H.N., Sung W.-K., Wong L. (2007) Using indirect protein interactions for the prediction of Gene Ontology functions, in: BMC Bioinformatics, BioMed Central, La Jolla, CA, USA, S8 p.

Dai C., Zhao J., Yan L., Zhao M. (2014) Adsorption behavior of cocamidopropyl betaine under conditions of high temperature and high salinity, J. Appl. Polym. Sci. 131, 40424.

Dang Cuong T.Q., Chen Z., Nguyen Ngoc T.B., Bae W., Phung T.H. (2011) Development and optimization of polymer conformance control technology in mature reservoirs: Laboratory experiments vs. field scale simulation, in: SPE Paper 144221 Presented at SPE Enhanced Oil Recovery Conference, Kuala Lumpur, Malaysia, pp. 19-21.

Elewaut K., Stavland A., Zaitoun A., Krilov Z., Zitha P.L.J. (2005) Investigation of a novel chemical for bullhead water shutoff treatments, in: SPE European Formation Damage Conference, May 25-27, 2005, Sheveningen, The Netherlands.

El-Mekawy R.E., Jassas R.S. (2017) Recent trends in smart and flexible three-dimensional cross-linked polymers: synthesis of chitosan- $\mathrm{ZnO}$ nanocomposite hydrogels for insulin drug delivery, MedChemComm 8, 897-906.

Elsharafi M.O., Bai B. (2012) Effect of weak preformed particle gel on unswept oil zones/areas during conformance control treatments, Ind. Eng. Chem. Res. 51, 11547-11554.

Evingür G.A., Pekcan Ö. (2014) Effect of multiwalled carbon nanotube (MWNT) on the behavior of swelling of polyacrylamide-MWNT composites, J. Reinf. Plast. Compos. 33, 1199-1206.

Farasat A., Sefti M.V., Sadeghnejad S., Saghafi H.R. (2017) Effects of reservoir temperature and water salinity on the swelling ratio performance of enhanced preformed particle gels, Korean J. Chem. Eng. 34, 1509-1516.

Fuseni A.B., AlSofi A.M., AlJulaih A.H., AlAseeri A.A. (2018) Development and evaluation of foam-based conformance control for a high-salinity and high-temperature carbonate, J. Pet. Explor. Prod. Technol. 8, 1341-1348.

Gaca K.Z., Parkinson J.A., Sefcik J. (2017) Kinetics of early stages of resorcinol-formaldehyde polymerization investigated by solution-phase nuclear magnetic resonance spectroscopy, Polymer 110, 62-73.

Gaca K.Z., Sefcik J. (2013) Mechanism and kinetics of nanostructure evolution during early stages of resorcinol-formaldehyde polymerisation, J. Colloid Interf. Sci. 406, 51-59.

Goudarzi A., Almohsin A., Varavei A., Delshad M., Bai B., Sepehrnoori K. (2014) New experiments and models for conformance control microgels, in: SPE Improved Oil Recovery Symposium, April 12-16, 2014, Tulsa, Oklahoma, USA.
Goudarzi A., Zhang H., Varavei A., Taksaudom P., Hu Y., Delshad M., Bai B., Sepehrnoori K. (2015) A laboratory and simulation study of preformed particle gels for water conformance control, Fuel 140, 502-513.

Gun'ko V.M., Savina I.N., Mikhalovsky S.V. (2017) Properties of water bound in hydrogels, Gels 3, 37 .

Helvacıŏlu E., Aydın V., Nugay T., Nugay N., Uluocak B.G., Şen S. (2011) High strength poly (acrylamide)-clay hydrogels, J. Polym. Res. 18, 2341-2350.

Jaisai M., Baruah S., Dutta J. (2012) Paper modified with ZnO nanorods-antimicrobial studies, Beilstein J. Nanotechnol. 3, 684-691.

Jia H., Ren Q., Li Y.M., Ma X.P. (2016) Evaluation of polyacrylamide gels with accelerator ammonium salts for water shutoff in ultralow temperature reservoirs: Gelation performance and application recommendations, Petroleum 2, 90-97.

Jiang L., Liu P. (2014) Design of magnetic attapulgite/fly ash/ poly (acrylic acid) ternary nanocomposite hydrogels and performance evaluation as selective adsorbent for $\mathrm{Pb} 2+$ ion, ACS Sustain. Chem. Eng. 2, 1785-1794.

Kalgaonkar R., Wagle V., Alnoaimi K., Alhussain I. (2017) Novel compositions based on nanomaterials designed for use as conformance sealants, in: Abu Dhabi International Petroleum Exhibition \&S Conference, November 13-16, 2017, Abu Dhabi, UAE.

Karimi S., Esmaeilzadeh F., Mowla D. (2014) Identification and selection of a stable gel polymer to control or reduce water production in gas condensate fields, J. Nat. Gas Sci. Eng. 21, 940-950.

Kumar A., Mahto V., Sharma V.P. (2020) Reinforced preformed particle gel: Synthesis, characterization and performance evaluation for water shut-off jobs in heterogeneous reservoir, J. Pet. Sci. Eng. 193, 107408.

Kumar A., Mahto V., Sharma V.P. (2019) Development of fly ash reinforced nanocomposite preformed particle gel for the control of excessive water production in the mature oil fields, Oil Gas Sci. Technol. - Revue d'IFP Energies nouvelles 74, 8.

Langford J.Il., Wilson A.J.C. (1978) Scherrer after sixty years: A survey and some new results in the determination of crystallite size, J. Appl. Crystallogr. 11, 102-113.

Lashari Z.A., Yang H., Zhu Z., Tang X., Cao C., Iqbal M.W., Kang W. (2018) Experimental research of high strength thermally stable organic composite polymer gel, J. Mol. Liq. 263, 118-124.

Li G., Zhang G., Wang L. (2013) Smart profile control by saltreversible flocculation of cationic microgels and polyacrylamide, Energy Fuels 27, 6632-6636.

Li T., Cao M., Liang J., Xie X., Du G. (2017) Mechanism of base-catalyzed resorcinol-formaldehyde and phenol-resorcinolformaldehyde condensation reactions: A theoretical study, Polymers 9, 426.

Li Z., Tang M., Dai J., Wang T., Bai R. (2016) Effect of multiwalled carbon nanotube-grafted polymer brushes on the mechanical and swelling properties of polyacrylamide composite hydrogels, Polymer 85, 67-76.

Liu Y., Bai B., Wang Y. (2010) Applied technologies and prospects of conformance control treatments in China, Oil Gas Sci. Technol. - Revue d'IFP Energies nouvelles 65, 859-878.

Liu Y., Dai C., Wang K., Zhao M., Zhao G., Yang S., Yan Z., You Q. (2016) New insights into the hydroquinone (HQ)hexamethylenetetramine (HMTA) gel system for water shutoff treatment in high temperature reservoirs, J. Ind. Eng. Chem. 35, 20-28. 
Liu Y., Dai C., Wang K., Zou C., Gao M., Fang Y., Zhao M., Wu Y., You Q. (2017) Study on a novel cross-linked polymer gel strengthened with silica nanoparticles, Energy Fuels 31, 9152-9161.

Ma K., Li A., Guo S., Pang J., Xue Y., Zhou Z. (2019) Techniques for improving the water-flooding of oil fields during the high water-cut stage, Oil Gas Sci. Technol. - Revue d'IFP Energies nouvelles 74, 69.

Mallakpour S., Javadpour M. (2016) The potential use of recycled PET bottle in nanocomposites manufacturing with modified $\mathrm{ZnO}$ nanoparticles capped with citric acid: Preparation, thermal, and morphological characterization, $R S C A d v$. 6, 15039-15047.

Michael F.M., Fathima A., AlYemni E., Jin H., Almohsin A., Alsharaeh E.H. (2018) Enhanced polyacrylamide polymer gels using zirconium hydroxide nanoparticles for water shutoff at high temperatures: Thermal and rheological investigations, Ind. Eng. Chem. Res. 57, 16347-16357.

Moradi-Araghi A. (2000) A review of thermally stable gels for fluid diversion in petroleum production, J. Pet. Sci. Eng. 26, $1-10$.

Okay O., Oppermann W. (2007) Polyacrylamide- clay nanocomposite hydrogels: Rheological and light scattering characterization, Macromolecules 40, 3378-3387.

Park H.E., Gasek N., Hwang J., Weiss D.J., Lee P.C. (2020) Effect of temperature on gelation and cross-linking of gelatin methacryloyl for biomedical applications, Phys. Fluids 32, 33102 .

Reena, Kumar A., Mahto V., Choubey A.K. (2020) Synthesis and characterization of cross-linked hydrogels using polyvinyl alcohol and polyvinyl pyrrolidone and their blend for water shut-off treatments, J. Mol. Liq. 301, 112472.

Rezaei A., Abdi-Khangah M., Mohebbi A., Tatar A., Mohammadi A.H. (2016) Using surface modified clay nanoparticles to improve rheological behavior of Hydrolized Polyacrylamid (HPAM) solution for enhanced oil recovery with polymer flooding, J. Mol. Liq. 222, 1148-1156.

Saikia T., Sultan A.S. (2020) Development of silane-modified colloidal silica pickering emulsion stabilized by organophilic micronized phyllosilicate for conformance control, J. Pet. Sci. Eng. 194, 107427.

Sang Q., Li Y., Yu L., Li Z., Dong M. (2014) Enhanced oil recovery by branched-preformed particle gel injection in parallel-sandpack models, Fuel 136, 295-306.

Seright R.S. (1991) Impact of dispersion on gel placement for profile control, SPE Reserv. Eng. 6, 343-352.

Sharifpour E., Riazi M., Ayatollahi S. (2015) Smart technique in water shutoff treatment for a layered reservoir through an engineered injection/production scheme, Ind. Eng. Chem. Res. 54, 11236-11246.
Singh R., Mahto V., Vuthaluru H. (2018) Development of a novel fly ash-polyacrylamide nanocomposite gel system for improved recovery of oil from heterogeneous reservoir, J. Pet. Sci. Eng. 165, 325-331.

Srivastava V., Choubey A.K. (2020) Kinetic and isothermal study of effect of transition metal doping on adsorptive property of zinc oxide nanoparticles synthesized via green route using Moringa oleifera leaf extract, Mater. Res. Expr. 6, $1250 i 7$.

Sudha, Mishra B.M., Kumar D. (2014) Effect of multiwalled carbon nanotubes on the conductivity and swelling properties of porous polyacrylamide hydrogels, Part. Sci. Technol. 32, $624-631$.

Sydansk R.D., Moore P.E. (1992) Gel conformance treatments increase oil production in Wyoming, Oil and Gas Journal, United States, 90 p.

Sydansk R.D. (1990) A newly developed chromium (III) gel technology, SPE Reserv. Eng. 5, 346-352.

Tongwa P., Baojun B. (2015) A more superior preformed particle gel with potential application for conformance control in mature oilfields, J. Pet. Explor. Prod. Technol. 5, 201-210.

Tongwa P., Nygaard R., Bai B. (2013) Evaluation of a nanocomposite hydrogel for water shut-off in enhanced oil recovery applications: Design, synthesis, and characterization, J. Appl. Polym. Sci. 128, 787-794.

Wassmuth F.R., Green K., Hodgins L. (2004) Water shutoff in gas wells: Proper gel placement is the key to success, in: SPE/ DOE Symposium on Improved Oil Recovery, April 17-21, 2004, Tulsa, Oklahoma.

Xindi S.U.N., Baojun B.A.I. (2017) Comprehensive review of water shutoff methods for horizontal wells, Petrol. Explor. Develop. 44, 1022-1029.

Zhang C., Qu G., Song G. (2017) Formulation development of high strength gel system and evaluation on profile control performance for high salinity and low permeability fractured reservoir, Int. J. Anal. Chem. 2017, 1-9

Zhao G., Dai C., Chen A., Yan Z., Zhao M. (2015) Experimental study and application of gels formed by nonionic polyacrylamide and phenolic resin for in-depth profile control, J. Pet. Sci. Eng. 135, 552-560.

Zhao G., Dai C., You Q., Zhao M., Zhao J. (2013) Study on formation of gels formed by polymer and zirconium acetate, $J$. Sol-Gel Sci. Technol. 65, 392-398.

Zhao G., Dai C., Zhao M., You Q. (2014) The use of environmental scanning electron microscopy for imaging the microstructure of gels for profile control and water shutoff treatments, J. Appl. Polym. Sci. 131, 39946.

Zhu D., Hou J., Wei Q., Wu X., Bai B. (2017) Terpolymer gel system formed by resorcinol-hexamethylenetetramine for water management in extremely higherature reservoirs, Energy and Fuels 31, 1519-1528. 